\title{
The Signaling Role of Municipal CurRencies IN LOCAL DEVELOPMENT
}

\author{
RAJSHRI JAYARAMAN \\ MANDAR OAK
}

CESIFo WORKING PAPER No. 913

CATEGORY 9: INDUSTRIAL ORGANISATION

APRIL 2003

An electronic version of the paper may be downloaded

- from the SSRN website:

www.SSRN.com

- from the CESifo website: www.CESifo.de 


\title{
THE Signaling Role OF Municipal CURRENCIES IN LOCAL DEVELOPMENT
}

\begin{abstract}
The last decade has seen the burgeoning of several hundred local community currency institutions in cities across the world. Although residents of these communities claim that local currency promotes local development, how if at all it does so has hitherto been unexplored. This paper argues that the introduction of a municipal currency may serve as a signal of demand for local goods. Where demand uncertainty deters firms from investing in more productive technologies, such a signal improves the chances that technology choice will be optimal. The introduction of a local currency therefore always improves ex-ante efficiency and may lead to ex-post efficiency, with strictly higher levels of productivity and welfare.
\end{abstract}

JEL Code: D8, O12, E4

Rajshri Jayaraman

CESifo (University of Munich \& Ifo Institute)

Poschingerstrasse 5

81679 Munich

Germany

Jayaraman@cesifo.de
Mandar Oak

Department of Economics

Fernald House

Williams College

Williamstown, MA 01267

U.S.A.

The authors would like to thank Larry Blume \& Steve Coate for valuable comments and suggestions They are also grateful to Kaushik Basu, Ted O'Donoghue, Salvador Ortigueira, Karl Shell, Özgür Toros and seminar participants at Cornell University for useful suggestions. 


\section{Introduction}

The town of Ithaca, New York, has a local currency, called Ithaca Hours, instituted by a local resident in 1991. Historically speaking, that a town should have its own local scrip is not an anomaly. Municipal currencies have a long and venerable history in the United States. They saw their heyday during the "Free Banking" era from 1837 to 1865, when there was no central bank, and again in the 1930s during the Great Depression. Today, Ithaca Hours is one of over 1,500 community currencies worldwide.

Why municipalities may have chosen to introduce their own currencies in the face of a collapsing or absent national currency is somewhat understandable. Why a town in the United States would choose to introduce its own currency in the late 20th century is more puzzling. Talking to local subscribers to the system, or visiting their web sites prompts a variety of responses. Some of these are simply not sensible. How, for instance, can using Ithaca Hours be credited for "raising the minimum wage" ? ${ }^{1}$ How can one claim the "Strength of [the] Ithaca Hour grows while the value of [the] dollar declines" when there is a fixed exchange rate? ${ }^{2}$ Two seemingly plausible explanations are that trading in Hours is a means of tax evasion or that they simply act as discount coupons. The former seems unlikely since income in Ithaca Hours must be declared - indeed, this was the original rationale for the federally-mandated fixed exchange rate between dollars and local currencies. The latter is, similarly, inaccurate since Ithaca Hour prices at local stores are posted at the fixed exchange rate, and never at an additional discount.

Upon hearing or reading many of these claims it is tempting; as an economist, to dismiss the Ithaca Hours phenomenon as an aberration. To do so, however, would be to ignore what is by far the most prominent (and most intriguing) rationale proferred by participants - one which underlies some of the more incredible claims. This is that "their own colorful currency is better

\footnotetext{
${ }^{1}$ www.ithacahours.org/genbennies.html

${ }^{2}$ www.ithacahours.com/archives.html
} 
for the local economy". ${ }^{3}$ The purpose of this paper is to analyse this claim.

The reason for our interest is at least threefold. First, Ithaca Hours is not an isolated phenomenon. Over 30 different towns in at least 18 different US states as well as numerous towns in Canada, Mexico, and Argentina are documented to have adopted the Hours system wholesale. ${ }^{4}$ There are estimated to be over 1000 local currency communities across North America and Europe, and many of which incorporate the salient features of the Ithaca Hours system. ${ }^{5}$ Local currency communities exist in at least 35 countries worldwide including all the EEC countries, as well as several developing countries such as Brazil, Equador, Thailand and Senegal, and have attracted international attention. ${ }^{6}$

Second, the mechanism is neither complex nor expensive. It has three salient features. First, dollars can be exchanged for Hours at a fixed exchange rate of 10 dollars to the Hour. (That the exchange rate be fixed is mandated by federal law for tax purposes.) Second, Hour holdings cannot be reconverted by consumers into dollars. Once held, then only way for consumers to get rid of local currency is to spend it. Third, Hours are accepted only at locally owned and operated businesses. Given these features, if one is interested in local development, the scheme is attractive in its sheer simplicity.

Finally, the claim itself poses an interesting puzzle for economists given the mechanism: one may use Hours to purchase local goods, but not to purchase goods at nationally owned chains (such as K-mart or Wegmans, a grocery store), whereas US dollars, as legal tender, can be used to purchase goods at either local or national stores. The question of why individuals

\footnotetext{
${ }^{3}$ Voice of America, Feb. 19, 1996, Interview with Margaret McCasland.

${ }^{4}$ www.ithacahours.com/otherhours.html

${ }^{5}$ Jeff Powell and Menno Salverda (1998): A Snapshot of Community Currency Systems in North America and Europe. Mimeo.

${ }^{6}$ For more information see http://ccdev.lets.net for a partial list of local currency systems across the world. Coverage of Ithaca Hours in mainstream papers include the New York Times, 1996 and The New Statesman, 1996.
} 
are willing to hold a seemingly dominated asset is one we will resolve as we answer the main question we set out to explore. This is: how might the use of a municipal currency promote local development?

The story we tell in this paper can be summarised as follows. Suppose you have an economy comprising a single local producer - say, a pumpkin farmer - and one good: pumpkins. Suppose also, that there are three consumers, each of whom are endowed with exactly one dollar which they can either spend buying pumpkins from the local farmer, or at the national grocery store.

The pumpkin farmer has two options: he can either sow his crop by hand, or he can make his life a little easier by buying himself a horse and using this to plant his seeds. If the farmer thinks that two or more consumers are going to buy his pumpkins, then it will be worthwhile for him to buy the horse. However, as things stand, he thinks that only one consumer is going to buy pumpkins from him, so he doesn't buy the horse but instead, plants his seeds laboriously by hand. The decision not to invest in the lower marginal cost technology (the horse) is, of course, ex-ante optimal: the farmer thinks that he will have only one customer. However, it may or may not be ex-post optimal. In particular, if two or three consumers end up buying pumpkins from the farmer, then he really should have bought the horse.

Suppose, now, that somebody comes along and offers consumers the option to dye their dollar red, but warns them: "if you dye your dollar red, you can use it only with the local farmer, but not at the grocery store". Then, if two or three people dye their dollar red, the farmer will invest in the horse, thereby making the ex-post efficient decision and enhancing local development.

The story told here is deliberately simple. A firm, when faced with a choice of technologies, may be unwilling to invest in "better" - lower marginal cost - technologies for fear that demand is insufficient to cover the investment necessary to acquire such technologies. If the firm does not expect that demand will be high enough to make such an investment worthwhile, then it 
will choose the less productive technology.

Whether such an investment decision is optimal ex-post obviously depends on demand realisations. The ex-post efficient outcome is one in which the firm chooses the more productive technology when actual demand is high, and the less productive technology when actual demand is low. Using the three salient features described above, we argue that local money serves as a signal of demand for local products, alleviating demand uncertainty, and improving ex-ante efficiency.

This paper is the first formal attempt (of which we are aware) to broach the topic of municipal currencies. As such, although it speaks to many strands of the economics literature on money, industrial organisation and development, it doesn't fit neatly into any extant literature. Its topic is "money", and although it provides a new rational for holding a particular scrip, it does not directly contribute to the vast macroeconomics literature on multiple currencies, dating back to Mundell's (1961) seminal work, or the macro literature on why we hold any money in the first place. It has to do with the effect of informational barriers to product market development, but not strictly in the IO tradition of, say, the infant industry protection literature of Grossman and Horn (1988). Like Rosenstein-Rodan (1943), Nurkse (1953) or Murphy, Shleifer and Vishny (1989), it deals with the topic of inadequate demand as a deterrent to development, but is not motivated by coordination failures and the "big push".

If one must place it anywhere in the literature, then perhaps the most appropriate place would be as an applied microeconomics paper on imperfect information and demand revelation. It should be noted here that this paper is provides one possible rationale for the phenomenon of municipal currencies. There are many other possible justifications for their existence, and we will discuss some of these at the end of the paper.

Section 2 presents the basic model. Section 3 considers the equilibrium of a game in which firms face a technology choice with demand uncertainty in the absence of a local currency. In section 4, we analyse the equilibrium 
of the game with local currency. Section 5 is devoted to seeing, through an example, how the introduction of a local currency compares to other, more traditional, policies directed at demand revelation. Finally, section 6 concludes.

\section{The Model}

Consider an economy consisting of $N$ consumers and one local firm. Each consumer's utility depends on his consumption of a local good $(l)$ and a national $\operatorname{good}(n)$. Utility, $u(l, n ; \theta)=\phi(l ; \theta)+n$, is quasi-linear in the local good, continuous, strictly quasi-concave, and increasing in both goods. There are two types of individuals: those who are very fond of the local good $-\theta_{H}$, or "High" types - and those who are not quite as fond of it $-\theta_{L}$, or "Low" types. Let $d(p, \theta)$ denote a $\theta$-type consumer's utility maximising level of local goods consumption subject to their budget constraint $p l+n \leq w$, where $p$ denotes the price of the local good, and $w$ is wealth (and is the same across all individuals). Then, what distinguishes a high type from a low type is that at any price $p>0$, a high type will demand more of the local good than a low type; that is, $d\left(p, \theta_{H}\right)>d\left(p, \theta_{L}\right)$. Types are distributed i.i.d., and are private information with the probability of observing a high type being $\bar{q}$ where $\bar{q} \in(0,1)$. If $q$ is the expected proportion of high types, therefore, aggregate expected demand may be denoted by $E D(p ; q)=N\left[q d\left(p, \theta_{H}\right)+\right.$ $\left.(1-q) d\left(p, \theta_{L}\right)\right]^{7}$

Before local currency enters the picture, wealth, $w$, is initially held

entirely in the national currency, say dollars $(D)$. With the introduction of a local currency, individuals will have the option of holding their currency in any combination of dollars or local money $(m)$, so that $w=m+D$. However, local money can be used towards the purchase of local goods but not towards the purchase of national goods, whereas dollars can be spent on

\footnotetext{
${ }^{7}$ We allow $q$ to be conditional upon some information; when there is no information, $q=\bar{q}$.
} 
either good. Holding positive amounts of a local currency which is not readily convertible into dollars therefore commits an individual to the purchase of the local good.

On the firm's side, there is a single local firm operating in a perfectly contestable market (p.c.m.) for local goods. The local firm is risk neutral and acts as an expected profit maximiser. There is nothing special about this market structure except that, as we will see in the following section, it guarantees a downward sloping price expansion path. ${ }^{8}$ There are two technology choices available to the local firm: $t \in\left\{t_{1}, t_{2}\right\}$. Under $t_{1}$, the firm can produce any amount of the good at a constant marginal cost of $c_{1}>0$. Under $t_{2}$, the firm faces a marginal cost of $c_{2}<c_{1}$, but must incur a per capita fixed cost of $F>0$.

The assumption of a per capita fixed cost is unusual, so it is worth spending some time justifying it. We are interested in studying a community in which the local producer faces a tradeoff in his choice of technology due to demand uncertainty. We claim that the local currency has a potential to resolve such uncertainty and thereby to facilitate adoption of the efficient technology.

The "high fixed costs-low marginal cost" technology is efficient only if the number of high types is above a certain threshold. Since each person has a positive probability of being a high type, as we consider larger and larger communities, the number of high types will (almost) always cross the threshold and this will mitigate the tradeoff faced by the local producer. By assuming that the fixed costs of adopting the said technology increase with the size of the economy, we retain the tradeoff faced by the producer- which is the situation that we are primarily interested in studying.

Assuming per capita fixed costs is but one convenient way of doing it. Any other formulation under which the fixed costs increase with community

\footnotetext{
${ }^{8}$ The analysis would be the same with Bertrand competition. However, Bertrand competition would entail carrying around an extra player without any added insight into the problem. We could also have had monopolistic or oligopolistic competition, with some added restrictions on the demand structure.
} 
size will retain our results. Moreover, the assumption of fixed cost being contingent on the size of the community is not unrealistic. Fixed costs include factors like rent/mortgage on the premises, costs of installing heavy machinery, etc. In a large community these costs will be higher. (For instance,think of the fixed costs of operating out of Ithaca vis-a-vis the New York City!)

So, if $E C(t, p)$ denotes the firm's expected total costs under technology $t$ and price $p$, then $E C\left(t_{1}, p\right)=c_{1} E D(p ; q)$ and $E C\left(t_{2}, p\right)=c_{2} E D(p ; q)+N F$.

Let $\eta(p, q)=\frac{\partial d(p, \theta)}{\partial p} \cdot \frac{p}{d(p, \theta)}, \theta$-type's price elasticity of demand, be elastic for all prices between $c_{1}$ and $c_{2}$. That is, for all $p \in\left[c_{2}, c_{1}\right],|\eta(p, q)| \geq 1$. This implies that in this price range, an individual will spend more on the local good as the price of this good decreases. So for every $p \in\left[c_{2}, c_{1}\right]$, $c_{1} d\left(c_{1}, \theta\right) \leq p d(p, \theta)$.

Given $q$, let $p(q)=\min \left\{p:\left(p-c_{2}\right) E D(p, q)-N F=0\right\}$ denote the minimum price such that profits are equal to zero under the second technology. Then, $p(q)$ satisfies the condition: $p(q)=c_{2}+\frac{N F}{E D(p(q), q)}$. Since $E D(p ; q)$ is increasing in $q$, clearly $p(q)$ is decreasing in $q$, that is, $p^{\prime}<0$.

The crux of this paper lies in the idea that demand uncertainty may breed inefficiency, and this has two parts. First, in the absence of information firms are unwilling to invest in the more productive technology $t_{2}$, due to insufficient expected demand. Second, we need to allow for the possibility that this decision is inefficient, that is, if expected demand were sufficiently (and feasibly) high, the firm would have optimally chosen $t_{2}$. These two ideas are, respectively, captured in the following two assumptions: $(i) p(\bar{q})>c_{1}$ and $(i i)$ there exists a $\widetilde{q} \in(\bar{q}, 1)$ s.t. $p(\widetilde{q})=c_{1} \cdot{ }^{9}$ The first assumption simply says that when the expected proportion of high types is $\bar{q}$ (the unconditional expectation), a firm pricing at average cost must charge a price above $c_{1}$ if it chooses $t_{2}$. We saw earlier that $p^{\prime}<0$. The second assumption therefore says

\footnotetext{
${ }^{9}$ These assumptions would have to be modified under alternative market structures. For example, under Bertrand competition, the first assumption would have to be $p\left(\frac{\bar{q}}{2}\right)>c_{1}$. The actual structure of

the assumptions is, however, only important insofar as it captures the idea of potential inefficiency arising from uncertainty.
} 
that there exists a feasible proportion of high-types $(\widetilde{q})$ above which a firm pricing at average cost can charge a lower price under the second technology than it can under the first.

\section{Game without local currency}

The game without local currency goes as follows. At the beginning of the period, nature reveals to each individual his type. This is private information; only the distribution of player types is common knowledge. The local firm then chooses a technology $(t)$ and price $(p)$. Consumers observe prices and decide how much of the local good to buy $(d(p, \theta))$. Finally, production and consumption take place.

An equilibrium of the game without local currency is a strategy for each consumer and a strategy $(t, p)$ for the local firm. The consumer's strategy in this game is simple: they simply demand $d(p, \theta)$ of the local good (and spend the remainder of their income on the national good). The firm's strategy follows from the three features of perfect contestability: (i) an entrant incurs no sunk costs of entry, (ii) an entrant is able to begin serving before an incumbent can change its price and (iii) entrants and incumbents have identical access to extant technologies. These three conditions effectively impose a zero-profit condition on the firm's side, hence inducing a downward sloping price expansion path. This, coupled with consumers' strategies gives rise to Lemmas 1 and 2, where we denote expected profits, by $E \pi(p)$.

Lemma 1 Under p.c.m., a firm which chooses $t=t_{1}$ must charge $p=c_{1}$.

Proof. Suppose $p>c_{1}$. Then, another firm could enter the market, under cut the price, and drive this producer out of business; $p<c_{1}$ implies $E \pi(p)<0$, which is strictly dominated by $E \pi\left(c_{1}\right)=0$

Lemma 2 Under p.c.m., a firm which chooses $t=t_{2}$ must charge $p=p(q)$

Proof. Analogous to Lemma 1 


\subsection{Equilibrium of the game without local currency}

Lemmas 1 and 2 give rise to the following equilibrium strategies for the firm and the consumers in the absence of a local currency.

Proposition 1 In the game without local currency, $\left(p^{*}, t^{*}\right)=\left(c_{1}, t_{1}\right)$,

$$
l\left(\theta_{H}\right)=d\left(p^{*}, \theta_{H}\right), \operatorname{andl}\left(\theta_{L}\right)=d\left(p^{*}, \theta_{L}\right)
$$

Proof. Suppose not; suppose the firm chose $t_{2}$. Then, from lemma 2 , and given that $q=\bar{q}$, we know that $p=p(\bar{q})>c_{1}$. So, from lemma 1 , an entrant could choose $t_{1}$ and profitably under cut the firm, leaving it with a loss of $N F$.

This proposition says that when a firm's only information regarding types is that the $\operatorname{Prob}\left(\theta=\theta_{H}\right)=\bar{q}$, it will choose the less productive technology $t_{1}$ and charge the high price $c_{1}$. This equilibrium may be regarded as a "lowlevel equilibrium" in the sense that productivity and demand are lower, and prices, higher than they would be under technology 2 .

However, the equilibrium may or may not be efficient in the ex-post sense. If the realised number of high-types in the economy is $K<\widetilde{q} N$, then the choice of technology $\left(t_{1}\right)$ is ex-post efficient. If, however, $K \geq \widetilde{q} N, t_{2}$ would Pareto dominate $t_{1}$, with the firm at least as well off and consumers strictly better off. The potential ex-post inefficiency arises on account of the firm's uncertainty regarding the distribution of consumer types, which in turn determines aggregate demand for their product. As we argue in the following section, the introduction of a local currency may actually allow consumers to signal their type costlessly, thereby allowing firms and consumers to coordinate on an equilibrium which is efficient both in the expected and ex-post sense.

\section{Game with local currency}

Now suppose that individuals have the option of holding a local currency, expendable only on local goods, and hence, serving as a signal of demand 
to local firms. The game with local currency runs as follows. First, nature reveals types. Each individual privately observes his type and then decides what portion of his (initially dollar) wealth to hold in local currency $(m)$. They then go to the monetary authority and convert this portion into $m$ at a fixed exchange rate. For simplicity, and without loss of generality, we assume this rate to be $1: 1$. Once converted, their local currency holdings cannot be reconverted into dollars and can only be spent on the purchase of local goods. The local firm observes the aggregate amount of local currency holdings $(M)$. It then updates its beliefs regarding the aggregate number of $\theta_{H^{-}}$ types in the economy - call this $h$ - and decides on a $(p, t)$ combination. Individuals observe prices and decide how much of the local good to buy. Market transactions then take place. At the end of the period, firms (but not consumers) can go to the monetary authority and redeem their local currency holdings for dollars.

A perfect Bayesian equilibrium of the game with local currency consists of a strategy for each consumer and a strategy and beliefs for the firm which satisfy the following properties. First, each consumer's strategy is optimal given other consumers' strategies and the firm's beliefs and strategy. Second, the firm's strategy is optimal given beliefs and consumers' strategies. Finally, beliefs are consistent.

As with most Bayesian games, this one has multiple equilibria, some of which are more reasonable than others. For example, there exists an equilibrium in which the firm believes that $h=0$ when $M \leq N w$, no one holds local currency, and the firm employs the high marginal cost technology. Given that individuals can only spend local currency on local goods, beliefs such as these seem somewhat unreasonable.

To capture the idea that firms recognise that local currency must be spent on local products, therefore, we restrict our attention to beliefs which satisfy the following simple monotonicity property. ${ }^{10}$ Let $\alpha(M)$ denote the firm's posterior regarding the number of $\theta_{H}$-types in the economy. Then,

\footnotetext{
${ }^{10}$ This refinement is used in a different context in Coate and Morris (1995).
} 
monotonicity implies that $\alpha\left(M^{\prime}\right) \geq \alpha(M)$ for all $M^{\prime}>M$, with $\alpha\left(M^{\prime}\right)>$ $\alpha(M)$ for some $M^{\prime}>M$ where $M, M^{\prime} \in[0, w N]$. In other words, observing a larger aggregate local currency holding cannot induce the firm to think that at any given price $p>0$, it will face a lower expected demand; furthermore, over some range of local currency holdings, the firm's beliefs regarding the proportion of high types in the economy is strictly increasing in $M$. The monotonicity assumption yields a unique equilibrium to the game with local currency, which has particularly intuitive properties, a couple of which coincide nicely with the characteristics of extant local currency systems.

\subsection{Equilibrium of the game with local currency}

Consider the problem of a consumer $i$ of type $\theta_{j}$. She must decide how much of her wealth to hold in local currency $\left(m_{i}\left(\theta_{j}\right)\right)$, and how much of the local good to consume $\left(x_{i}(p, m)\right)$. When the firm has monotone beliefs, the consumer knows that holding more local currency may convince the firm that there are enough high types to choose $t_{2}$ and charge a lower price. However, the danger in holding local currency is that at any given price $p$, she may be stuck with more of the local currency than she would optimally like to spend on the local good. This problem would be overcome if the consumer held the minimum amount she would spend on the local good irregardless of the firm's technology choice and other consumers' strategies or, more precisely, an amount:

$$
m_{i}\left(\theta_{j}\right)=\min _{p \in\left[c_{1}, c_{2}\right.} p d\left(p, \theta_{j}\right)
$$

Since $|\eta(p, q)| \geq 1$ for all $p \in\left[c_{2}, c_{1}\right]$, we know that $m_{i}\left(\theta_{j}\right)=c_{1} d\left(c_{1}, \theta_{j}\right)$. That is, the consumer's strategy is to hold that amount which she would spend on the local good if the firm were to stick to the less productive technology; notice that $m\left(\theta_{H}\right)>m\left(\theta_{L}\right)$ since $d\left(p, \theta_{H}\right)>d\left(p, \theta_{L}\right)$. If a consumer follows this money holding strategy, then her local goods consumption will be: 


$$
x_{i}\left(p, m_{i}\right)=\max \left\{d\left(p, \theta_{j}\right), \frac{m_{i}}{p}\right\}
$$

Given that individuals are following this strategy, aggregate money holdings in the economy are $M=\sum_{i=1}^{N} m_{i}\left(\theta_{j}\right)=K m\left(\theta_{H}\right)+(N-K) m\left(\theta_{L}\right)$, where $K$ is the number of

high-types in the economy. The firm knows the aggregate local money holdings in the economy and, in equilibrium, beliefs must be consistent with consumers' strategies. ${ }^{11}$ Therefore, re-arranging this equation and solving for $K$, the firm's (equilibrium) beliefs regarding the number of high-types in the economy naturally take the following form:

$$
\alpha(M)=\frac{M-N m\left(\theta_{L}\right)}{m\left(\theta_{H}\right)-m\left(\theta_{L}\right)}
$$

Hence, if $m\left(\theta_{L}\right)$ and $m\left(\theta_{H}\right)$ denote low- and high-type consumers' equilibrium money-holding strategies, in observing the aggregate money holdings in the community the firm will be able to perfectly intuit the aggregate number of high-types in the economy. It is in this manner, therefore, that holding local currency signals demand. Let $\widetilde{K}=\widetilde{q} N$ be the critical number of high-types above which a firm will be induced to choose $t_{2}$ and let $\widetilde{M}=m\left(\theta_{H}\right) \widetilde{K}+m\left(\theta_{L}\right)(N-\widetilde{K})$. Then, the firm's equilibrium price-technology strategy is then very straight forward given its beliefs and consumers' strategies. It is given by:

$$
(p, t)=\left\{\begin{array}{cc}
\left(c_{1}, t_{1}\right) & \text { if } M<\widetilde{M} \\
\left(c_{2}+\frac{N F}{E D\left(p ; \frac{\alpha(M)}{N}\right)}, t_{2}\right) & \text { if } M \geq \widetilde{M}
\end{array}\right.
$$

In other words, if a firm sees "enough" local money in the community $(M \geq \widetilde{M})$, it will choose the more productive technology and charge a lower

\footnotetext{
${ }^{11}$ In Ithaca, information regarding the aggregate local money holdings is explicitly provided in a bi-monthly newspaper called "Hour Town".
} 
price. Otherwise, it will resort to the less productive technology. Proposition 2 describes equilibrium strategies and beliefs formally.

Proposition 2 If $N$ is sufficiently large, in a game with local currency the following is a Perfect Bayesian Equilibrium with monotonic beliefs:

(i) Consumer i's money-holding and local goods consumption strategies are described by (1) and (2) respectively, where $i \in\{1, \ldots N\}$ and $j \in\{L, H\}$.

(ii) The firm's price-technology strategy is given by (4)

(iii) The firm's beliefs are of the form described in (3)

Proof. Given consumers' strategies and the beliefs outlined in (i) and (iii), the firm's equilibrium strategy follows from Lemmas 1 and 2 and Proposition 1. Furthermore, given a money-holding strategy; consumer's local goods consumption follows naturally. Consider consumer $i$ 's money-holding strategy.

First consider a deviation to the left: $m^{\prime} \in[0, m(\theta))$. Let $M^{\prime}=M-\left(m(\theta)-m^{\prime}\right)$. For an individual of type- $\theta$, there exist three possibilities.

(1) $\alpha\left(M^{\prime}\right) \geq \widetilde{K}$

In this case, the firm chooses $t_{2}$ regardless of the individual's deviation. Average cost pricing and the monotonic beliefs property (m.b.p.) mean, however, that the individual stands to face a higher price, leaving him strictly worse off holding $m^{\prime}$ rather than $m(\theta)$.

(2) $\alpha(M)<\widetilde{K} \Rightarrow \alpha\left(M^{\prime}\right)<\widetilde{K}$ under m.b.p.

Here, the firm always chooses $t_{1}$ and charge $c_{1}$, so the individual is indifferent between holding $m(\theta)$ and $m^{\prime}$.

(3) $\alpha(M) \geq \widetilde{K}$ and $\alpha\left(M^{\prime}\right)<\widetilde{K}$. 
That the individual will induce a switch from $t_{2}$ to $t_{1}$ and hence face a higher price is a positive probability event for any $m^{\prime}<m(\theta)$. Such an action would therefore make the deviator strictly worse off. Given that the individual is indifferent in case 2, but strictly worse off under cases 1 and 3, under m.b.p., the individual will never have an incentive to deviate to a lower $m(\theta)$.

Now, consider a deviation to the right: $m^{\prime} \in(m(\theta), w]$. Without loss of generality, normalise $m\left(\theta_{L}\right)=0$ and $m\left(\theta_{H}\right)=1$. We first introduce some notation. Let $v_{j}(p)=u\left(d\left(p, \theta_{j}\right), w-p d\left(p, \theta_{j}\right)\right)$ be a type- $\theta_{j}$ consumer's indirect utility at his optimal consumption bundle at price $p$. Let $\mathrm{v}_{j}(p, m)=u\left(x_{j}(p, m), w-p x_{j}(p, m)\right)$, be a type- $\theta_{j}$ consumer's maximum possible utility at price $p$ when he holds $m$ units of the local currency, where as before, $x_{j}(p, m)=\max \left\{d\left(p, \theta_{j}\right), \frac{m}{p}\right\}$. Notice that $v_{j}(p) \geq \mathrm{v}_{j}(p, m) \forall m, p$. Finally, let $\delta_{j}(p, m)=\mathrm{v}_{j}(p, m)-v_{j}(p)$. Clearly, $\delta_{j}(p, m) \leq 0$.

Consider a $\theta_{H^{-}}$-type's incentive to deviate to $m^{\prime} \in(m(\theta), w]$. (An analogous argument works for a $\theta_{L}$-type, so we omit it here.) Let $\left[\widetilde{K}-m^{\prime}\right]$ be the biggest integer smaller than $\left(\widetilde{K}-m^{\prime}\right)$, and let $s=h$. Then with i.i.d. types, there are three possible states. In the first, the firm always chooses technology 1 and charges $p=p(\alpha(M))=p\left(\alpha\left(M^{\prime}\right)\right)=c_{1}$. In the second, holding $m^{\prime} \in(m(\theta), w]$ may induce the firm to switch from technology 1 to technology 2 and charge

$p=p\left(\alpha\left(M^{\prime}\right)\right)=c_{2}+\frac{N F}{\alpha\left(M^{\prime}\right) d\left(p\left(\alpha\left(M^{\prime}\right)\right), \theta_{H}\right)+\left(N-\alpha\left(M^{\prime}\right)\right)\left(d\left(p\left(\alpha\left(M^{\prime}\right)\right), \theta_{L}\right)\right)}$.

In the third, the firm always chooses technology 2 and charges $p=p\left(\alpha\left(M^{\prime}\right)\right)$.

State 1: $h \leq \widetilde{K}-m^{\prime}$ with probability $\rho_{1}=\sum_{s=0}^{\left[\widetilde{K}-m^{\prime}\right]-1}\left(\begin{array}{c}N-1 \\ s\end{array}\right) \bar{q}^{s}(1-\bar{q})^{N-1-s}$

State $2: \widetilde{K}-m^{\prime}<h \leq \widetilde{K}-1$ with probability 
$\rho_{2}=\sum_{s=\left[\widetilde{K}-m^{\prime}\right]-1}^{\widetilde{K}-2}\left(\begin{array}{c}N-1 \\ s\end{array}\right) \bar{q}^{s}(1-\bar{q})^{N-1-s}$

State $3: h \geq \widetilde{K}$ with probability

$\rho_{3}=\sum_{s=\widetilde{K}-1}^{N-1}\left(\begin{array}{c}N-1 \\ s\end{array}\right) \bar{q}^{s}(1-\bar{q})^{N-1-s}$

Let $\widetilde{K}=a N$ where $a \in(0,1)$ and let $B(r)$ be the benefits to the deviator when the state of the world is $r$. Then, $B(1)=\delta_{H}\left(c_{1}, m^{\prime}\right)<0$ since $m^{\prime}>m\left(\theta_{H}\right)=c_{1} d\left(c_{1}, \theta\right)$, and $B(3)=\left(\mathrm{v}_{H}\left(p\left(\alpha\left(M^{\prime}\right), m^{\prime}\right)-\right.\right.$ $v_{H}\left(p\left(\alpha\left(M^{\prime}\right)\right)\right) \lesseqgtr 0$. In State 2 , holding $m^{\prime} \in(m(\theta), w]$ induces the firm to switch from technology 1 to technology 2 . The benefit to the deviator in this state is $B(2)=\left(\mathrm{v}_{H}\left(p\left(\alpha\left(M^{\prime}\right), m^{\prime}\right)-v_{H}\left(c_{1}\right)\right) \lesseqgtr 0\right.$.The total expected net benefit from deviating is therefore:

$$
E B(r)=\rho_{1} B(1)+\rho_{2} B(2)+\rho_{3} B(3)
$$

The first expression is always negative, and the last two have ambiguous sign. At worst, $B(2), B(3)>0$. However, as $N$ gets large, $\rho_{3}, \rho_{2} \rightarrow 0$ and $\rho_{1} \rightarrow 1$. So, $E B(r) \rightarrow E B(1)<0$. Therefore, for large $N$, the individual has no incentive to deviate to $m^{\prime} \in(m(\theta), w]$.

Finally, check that beliefs are correct in equilibrium (they are).

Remark The equitibrium with monotonic beliefs described in proposition 2 is unique.

This proposition and the remark above together say that in the unique equilibrium of the game with local currency, each individual holds the minimum amount they will spend on the local good-regardless of what technology is eventually chosen - in the local currency. Firms, having observed the aggregate level of local currency holdings, perfectly infer the number of $\theta_{H}$-types in the economy. 
Consumers' equilibrium strategies are driven by the monotonicity of beliefs, which captures the idea that firms recognise the signaling potential of local money holdings. On one end, monotonic beliefs ensure that holding less than the minimum is a weakly dominated strategy. However, this becomes problematic at the other end. Although the individual never has an incentive to hold this amount in state 1 , by this very property, individuals may be induced to hold more than their minimum in order to either lower prices in state 3 or induce a technology switch with lower prices in state 2 . However, if $N$ is big, the probability of being in the first state (in which you make a certain loss by over-holding) is big compared to the probability of being in states 2 or $3 .^{12}$ Therefore, the net benefit of deviations to the right is negative. It is precisely this logic which gives rise to the uniqueness of this equilibrium. For each consumer $i$, monotonicity rules out money holdings to the left of the minimum, and as we just saw, for sufficiently large $N$, money holdings larger than the minimum are ruled out as well. ${ }^{13}$

The equilibrium described in proposition 2 has several appealing properties. First, a symmetric equilibrium arises naturally from the consumers' strategies, considerably simplifying the construction of the firm's beliefs. Second, as mentioned in the introduction, casual intuition suggested that holding local currency is a weakly dominated strategy - dollars can be used

\footnotetext{
${ }^{12}$ This is akin to the voting literature in that with large $N$, the probability of being pivotal in affecting the outcome is small.

${ }^{13}$ We believe the demand elasticity assumption to be an accurate representation of reality, since the goods typically sold in these markets are low-priced luxuries such as candles, honey and pottery. However, it is technically non-trivial since it ensures that the minimum holding is attained at expenditures under technology 1 . If this were not the case - if the minimum is hit at expenditure under technology 2 instead - then the following problem would arise. We know that the benefits from holding more than the minimum in this case are strictly negative in state 3 . As $\mathrm{N}$ becomes large, the probability of being in state 3 goes to zero faster than the probability of being in state 2 (and earning a potentially positive benefit). Although being in states 2 or 3 becomes a zero measure event as $\mathrm{N}$ goes to infinity, one can no longer rule out the possibility that there exist profitable deviations greater than the minimum at technology 2 expenditure.
} 
to buy both national and local goods whereas local currency can only be used towards the purchase of the local good. However, a local currency has a supplementary attribute over and above being a unit of exchange: it serves a signal of demand for local products. Monotonicity coupled with the min-strategy therefore turns conventional intuition on its head, making the holding of local currency a weakly dominant strategy over a certain range.

Third, efficiency arises even when individuals are following a particularly pessimistic strategy. In many coordination games, efficiency arises when players shoot for the moon at a potential cost, and this optimistic strategy becomes self-fulfilling. Here, people are acting in such a manner that even if the firm does not charge the lower price, they will not be hurt by their chosen strategies.

Fourth, individuals who are more keen about local goods hold larger amounts of the local currency; this is widely observed in practice. Finally, the equilibrium captures the fact that the actual amount of local currency in circulation tends to be small. ${ }^{14}$ In this model, this could be explained by a combination of low demand for the local good at current prices as well as consumers' min-strategies.

\section{$5 \quad$ Alternative Policies}

The introduction of a local currency provides individuals with an instrument to signal their demand for local goods; it essentially acts as a demand revelation mechanism. In the equilibrium we have constructed, such a signal is perfectly revealing and can have one of two consequences. When the local firm's posteriors are sufficiently high, it switches to a more productive technology, charging a lower price. When they are sufficiently low, the firm stays with the less productive technology - the one they would have cho-

\footnotetext{
${ }^{14}$ In Ithaca, the total amount of local money in circulation amounts to a mere 64,000 USD. However, this amount is not an insignificant part of the local economy; on any given day at the farmer's market, 5 to 20 per cent of trade takes place in Ithaca Hours.
} 
sen in the absence of any signal. In equilibrium, firms earn zero expected profits, so, since they are risk neutral, firms are certainly no worse off under a local currency regime. By holding what they would spend on the local good anyway, consumers are never worse off when demand is revealed to be low. Furthermore, they are strictly better off when demand is revealed to be high. In the equilibrium we have constructed, therefore, the introduction of a local currency therefore always leads to a Pareto improvement: efficiency is enhanced in both an ex-ante and an ex-post sense. ${ }^{15}$

Ex-post optimality arises because in this equilibrium, the introduction of a local currency effectively induces truth-telling. Needless to say, the introduction of a local currency is not the only demand revelation mechanism available to policy makers. It would be instructive, therefore, to see how this policy compares to other demand revelation mechanisms a government may resort to.

One obvious candidate is a survey: the government could simply go out and ask each individual what their type is. However, since all low types will claim to be high types, any such survey must be accompanied by an incentive for truth-telling.

Consider the following mechanism. Suppose that rather than introduce a local currency, local goods production is organised in the public sector and the government pursues the following policy. First, it asks individuals to reveal their type. On the presumption that announcements are true, the government then chooses the appropriate technology in precisely the same manner as the firm did previously. In particular, it selects $t_{1}$ and charges a price $p=c_{1}$ if the proportion of self-declared $\theta_{H}$-types $\left(r=\frac{R}{N}\right)$ is less than $\tilde{q}$; it chooses $t_{2}$, setting $p=\min \left(A C\left(t_{2} ; r\right)\right)$, otherwise. Trade then takes place at this price. If demand realisations are at variance with the anticipated demand, any profits or losses incurred by the government-producer are passed

\footnotetext{
${ }^{15}$ Note that by imposing a zero-profit condition, the market structure we adopt allows us to talk unambiguously about Pareto improvements. With other market structures we would have to consider more conventional measures such as surplus maximisation.
} 
on to consumers in the form of lump-sum transfers or taxes, $\tau{ }^{16}$

In analysing this policy, closed form solutions are intractable. The appendix of this paper presents a numerical example with graphical illustrations instead. As the example shows, it is possible to obtain full demand revelation when the transfer is targeted to the transgressor. Under such a policy, any given individual contemplating a unilateral deviation from truth-telling faces a trade off between a price difference on the one hand and transfers or tax on the other. For high (low) types, the former (latter) effect dominates. Although this sounds promising, it is important to recognise that a targeted policy has lavish book-keeping requirements. In order to enforce such a policy, the government must keep a record of names on both announcements and transactions. This promises to be an extremely complex, not to mention expensive, undertaking - arguably more so than printing local money.

The example further demonstrates that once you move to a less exacting system of taxation based on aggregate indicators, you lose the truth-telling equilibrium. In particular, when a targeted tax is substituted with a head tax, low-types now have an incentive to announce that they are high-types because they continue to reap the benefit of the resultant price reduction, while bearing only a fraction of the tax costs.

In the equilibrium described in Proposition 2 and illustrated in the example, however, a local currency policy essentially succeeds where the head-tax fails; firms are able to divine the number of high-types in the economy simply by observing aggregate money-holdings in the economy $(M)$.

Besides being relatively inexpensive to administer and having minimal

\footnotetext{
${ }^{16}$ This policy, in effect, imposes a balanced budget constraint on the government. The restriction serves a dual purpose. First, it guarantees that the firm will earn zero-profits, thereby facilitating Pareto comparisons in equilibrium under this policy. Second, it enforces a discipline on punishment which may otherwise be taken to extremes in order to induce the desired (efficient) outcome in equilibrium. For example, the government could ask individuals to reveal their types and then kill everyone if observed demand were not in accordance with announcements. In equilibrium, then, all individuals would tell the truth, but such a policy is simply not reasonable.
} 
book-keeping requirements, local currency has the additional appeal of being decentralised and self-enforcing. The government's only function is to play the role of the monetary authority, printing and exchanging local currency. It need not worry about implementing punitive measures on consumers since, in deviating from their "min" strategy (which is analogous to truth-telling), players impose a potential cost upon themselves in terms of sub-optimal consumption.

Granted, this task involves both the cost of printing money and a certain degree of credibility. Neither individuals nor firms would be willing to trade in the local currency if they did not trust the monetary authority to play the role of facilitator in an honest manner. However, the same would be true of standard tax/transfer policies designed to elicit truth-telling. These involve not only the assurance that the government will not simply pocket any gains, but also that it will set policy in order to enhance efficiency, assuming that it has taxation authority at all. These are, if anything, a more stringent set of requirements.

\section{Conclusion}

How might the use of a municipal currency promote local development? This paper argues that local money serves as a signal of demand for local goods. This attenuates demand uncertainty and enhances efficiency.

In the equilibrium we constructed money holdings are fully revealing; leading to ex-post optimality. Indeed, for any finite number of local firms producing a finite number of goods, this will be the case as long as firms know $d(p, \theta)$, the vector of demands for each firm's good. Once we allow for more than two consumer types, however, the particular signal we considered no longer induces an information structure without noise. This is because a firm, in observing only $M$, has one equation in more than one unknown $(J-1$ unknowns if there are $J$ consumer types). Although residual uncertainty would mean that ex-post efficiency is no longer assured in this case, such a 
signal would nonetheless be informative. The important thing to notice is that the introduction of a local currency voluntarily held by optimising agents never increases firms' demand uncertainty and although ex-post efficiency is by no means guaranteed, ex-ante efficiency is always (weakly) improved. At worst, posteriors and priors are identical and at best, as in the equilibrium of the game we considered earlier, demand is perfectly revealed. Moreover, as we argued in the previous section, the institution is attractive in its sheer simplicity.

Our suggestion that the introduction of a local currency in such an institutional serves to resolve demand uncertainty has at least two limitations. First, once uncertainty on the part of consumers regarding their own demand for the local good is introduced, local currency once more becomes a dominated asset. To some extent, this explains why individuals who hold local currency tend to be those who are well settled in the local community. More generally, however, it does suggests that the analysis would not go through in a climate of individual uncertainty in the absence further structure.

Second, as monetary theorists well recognise, the introduction of a new currency is no easy matter. In focusing on the introduction of a local currency to supplement a national one, we have skirted at least two important issues. The first is the level of credibility with which we have exogenously endowed the monetary authority. Clearly, if firms did not trust the monetary authority to redeem their local currency for dollars, this policy would never get off the ground. It is noteworthy in this respect that local community currencies are typically founded by individuals with deep roots in a community. Second, there looms the issue of why people are willing to hold money at all. At the very least, a dynamic framework would be required to answer this broader question.

This paper has offered one possible rationale for the introduction of a local currency. There are numerous other candidates. For example, members of local currency communities often claim that the use of a local currency cultivates a sense of community. It is not difficult to formalise this idea in 
a model in which national and local goods are substitutes and consumers' utility of local goods consumption increases in the number of agents consuming locally. Such a model would essentially be a coordination game with two equilibria. In the "good equilibrium", everyone consumes locally and in the "bad equilibrium", nobody consumes locally. The introduction of a local currency would then help agents to coordinate on the "good" equilibrium by signaling their intent to consume locally.

More generally, local currency institutions come in a number of different variations, of which the Ithaca Hours system is only one. These include Local Exchange Trading Systems (LETS) which operate on an explicit system of reciprocity, and systems in which money is printed and distributed rather than exchanged for national currency. Although each of these institutions claim to promote local development, the mechanism through which this transpires would be different than that depicted in this model's institutional setting. In particular, LETS bears a striking resemblance to Kocherlakota's (1998) notion of money as memory - a record of gift giving. By contrast, a model for cash wealth-creation-type of local currency would have to explain why a national currency does not suffice. This would probably involve describing a non-information-based market failure which leads to a (dollar) cash constraint among a subset of the population who would otherwise like to trade with one another.

For microeconomists, thinking about the rationale for indigenous institutions of this type gives one a great deal of insight into the nature of market failures individuals perceive as deterrents to development, as well as mechanisms for overcoming them. For monetary economists, future investigation of LETS and wealth-creation institutions may prove to be a useful playground in scrutinizing the nature of money. 


\section{Bibliography}

Coate, Stephen and Stephen Morris (1995): "On the Form of Transfers to Special Interests". Journal of Political Economy 103(6): 1210-1235.

Glover, Paul (1995): Hometown Money: How to Enrich Your Community with Local Currency. Mimeo.

Grossman, Gene and Henrik Horn (1988): "Infant-Industry Protection Reconsidered: The Case of Informational Barriers to Entry". Quarterly Journal of Economics 103(4): 767-787.

Kiyotaki, Nobuhiro and Randall Wright (1993): "A Search-Theoretic Approach to Monetary Economics". American Economic Review 83(1): $63-77$.

Kocherlakota, Narayana (1998): "Money is Memory", Journal of Economic Theory, 81(2): 232-41.

Kocherlakota, Narayana and Thomas Krueger (1999): “A Signaling Model of Multiple Currencies". Review of Economic Dynamics 2: 231-244.

Mundell, Robert (1961): "A Theory of Optimal Currency Areas". American Economic Review 51: 509-517.

Murphy, Kevin, Andrei Shleifer and Robert Vishny (1989):

"Industrialization and the Big Push", Journal of Political Economy 97(5): 1003-1026.

New York Times (1996): “Pocket Money For Everyman”, Jan. 21, p. 21.

New Statesman (1996): "A town that prints its own money", Aug. 2, p. 18.

Nurkse, Ragnar (1953): Problems of Capital Formation in Underdeveloped Countries. New York: Oxford University Press.

Rosenstein-Rodan, Paul (1943): "Problems of Industrialisation in Eastern and South-eastern Europe". Economic Journal 53: 202-211. 


\section{Appendix}

Consider an economy comprising 100 individuals $(N=100)$ with linear demand functions of the form $d(p, \theta)=\theta-p$, where $\left(\theta_{H}, \theta_{L}\right)=(12,8) \cdot{ }^{17}$ Let each individual's wealth be $w=60$ and let the probability of an individual being of type $\theta_{H}$ be $\bar{q}=0.45$. Then, if $F=0.8, c_{1}=0.62$ and $c_{2}=0.6$, $\widetilde{q}=0.5$. Let $a_{i}$ denote person $i$ 's announcement of his type, where $a_{i}=1$ if he announces that he is a high type, and $a_{i}=0$ if he announces that he is a low type. Then, $R=\sum_{i} a_{i}$ is the total number of individuals announcing high types and let $r=\frac{R}{N}$. Let $E D(p ; R)=R d\left(p, \theta_{H}\right)+(N-R) d\left(p, \theta_{l}\right)$ denote the expected demand for the local product following individuals' announcements of types, under the presumption that individuals are telling the truth. We know that when $r<0.5$, the government will choose technology 1 and set a price $p(R)=0.62$; and when $r \geq 0.5$ it will choose technology 2 and set a price $p(R)=0.6+\frac{N F}{E D(p ; R)}$. Let $\pi(R, K)$ denote the government's (realised) profits when $R$ individuals announce that they are $\theta_{H}$-types and $K$ individuals act like $\theta_{H}$-types. Then, under the policy outlined above, the government's total tax/transfer bill will be: $\tau(R, K)=\pi(R, K)$, where $\pi(R, K)=N\left[\left(\frac{K}{N} d\left(p(R), \theta_{H}\right)+\left(1-\frac{K}{N}\right) d\left(p(R), \theta_{L}\right)\right)(p(R)-0.6)-0.8\right]$ when $R>50$ and $\pi(R, K)=0$ otherwise. Clearly, whenever $R>K, \pi(R, K) \leq 0$ and when $R<K, \pi(R, K) \geq 0$.

What we are really interested in is whether a given tax schedule will induce truth-telling $(K=R)$. In order to answer this question, we need to determine whether there exist profitable deviations from truth-telling. This means that we can restrict our attention to two cases: (i) $R=K+1$ and (ii) $R=K-1$. The first case pertains to a $\theta_{L^{-}}$type pretending to be a $\theta_{H^{-}}$ type. The second case pertains to a $\theta_{H}$-type pretending to be a $\theta_{L}$-type. Let $v_{i}\left(p(R), \theta_{-j} \mid \theta_{j}\right)=u\left(d\left(p(R), \theta_{j}\right), w-p(R) d\left(p(R), \theta_{j}\right)\right)+\tau_{i}(R, K)$ denote the net benefit of lying for an individual $i$ of type $\theta_{j}$. Then, if $E v_{i}\left(p(R), \theta_{-j} \mid \theta_{j}\right)>$

\footnotetext{
${ }^{17}$ A utility function of the form $u(l, n ; \theta)=\frac{1-(\theta-l)^{2}}{2}+n$ would, for example, produce such a demand function.
} 
$E v_{i}\left(p(R), \theta_{j} \mid \theta_{j}\right)$, a type $\theta_{j}$ will be better off lying when others are telling the truth.

First consider the case in which the government targets any taxes or transfers directly to the deviator. That is, if $i$ deviates whilst everyone else tells the truth, $\tau_{i}(R, K)=\pi(R, K)$ and $\tau_{-i}(R, K)=0$.

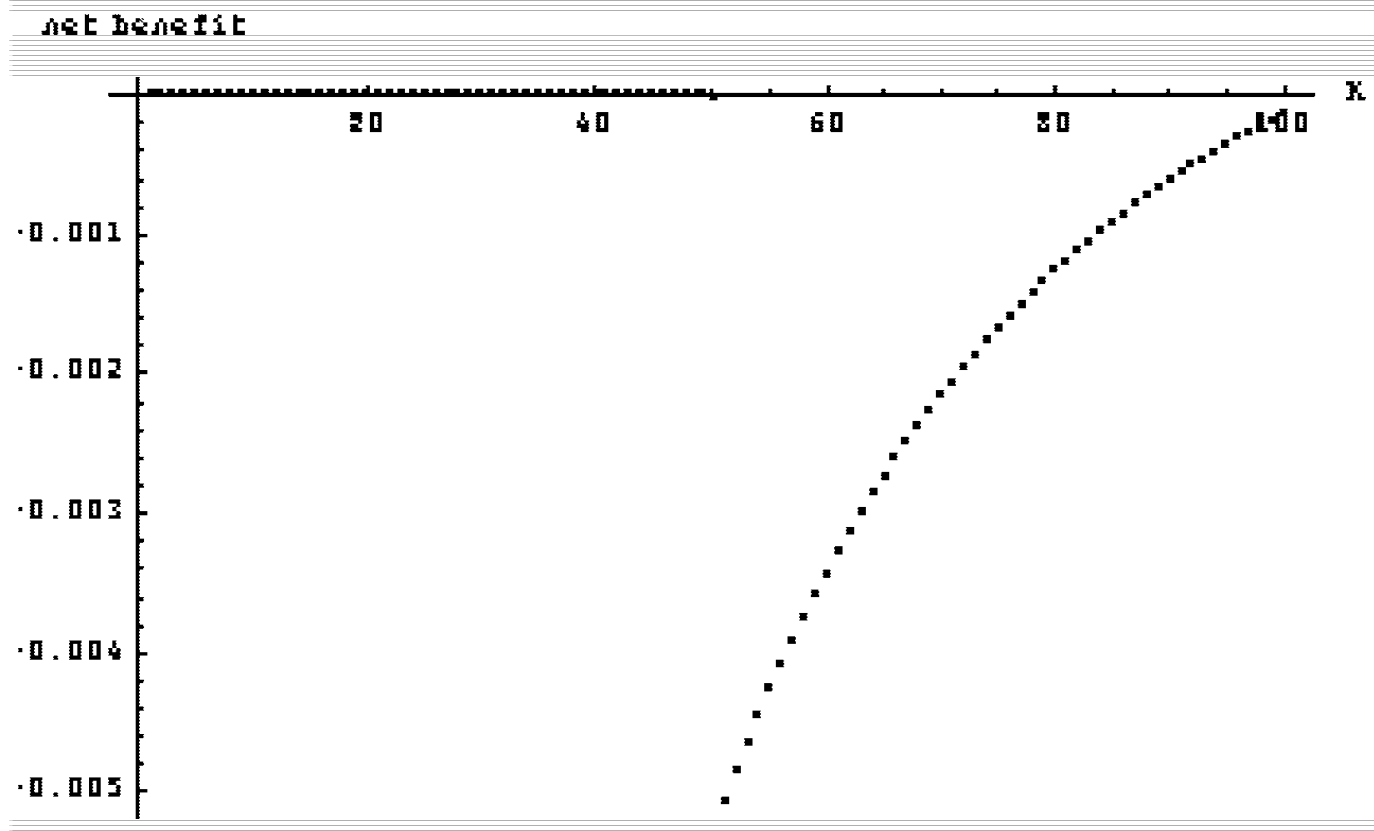

Figure 1: Net benefit to High-type deviating under targeted transfers

As we can see in figure 1, a high type has no incentive to deviate in any state of the world (i.e. for any $K$ ). For $K \leq 50$, the deviation does not cause any change in price and the government earns zero profits. Hence, in this range, there is no tax or transfer. For $K>50$, the net benefit (positive transfer from government's profits, less the utility loss from a higher price) is negative. Thus, the expected benefit from lying is negative. Similarly, as figure 2 indicates, a low type has no incentive to deviate from truth-telling either. 


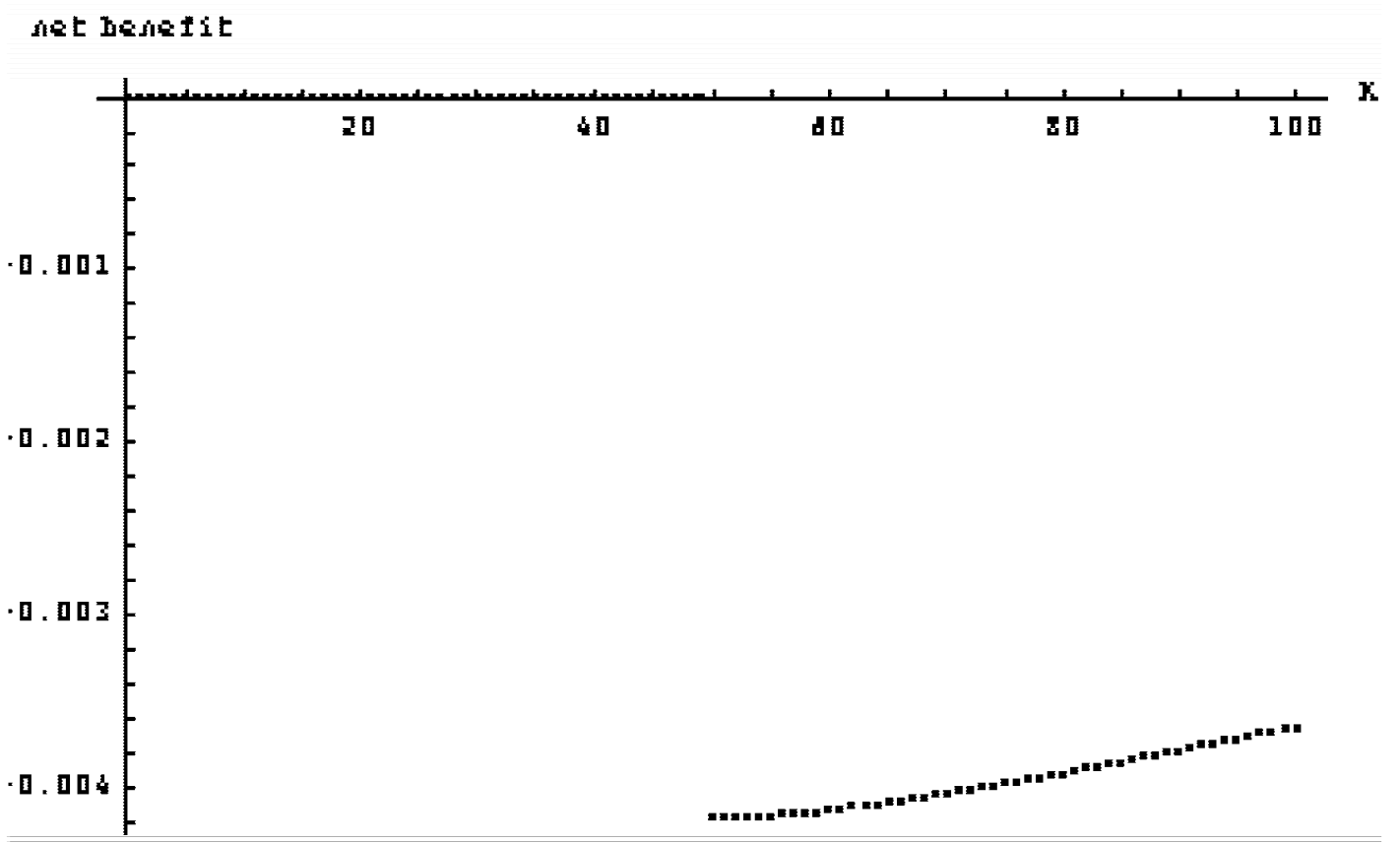

Figure 2: Net Benefit to a Low-type deviating under targeted transfers

The targeted tax/transfer policy therefore induces truth-telling. Rather than a targeted policy, consider a simple head-tax/transfer of the form $\tau_{i}(R, K)=$ $\frac{\pi(R, K)}{N}$ for all $i$. Figures 3 and 4 depict the incentives for deviation under this policy.

The costs incurred by high-type deviating from truth-telling are magnified when the government institutes a per-capita rather than a targeted transfer. Consequently, as seen in figure 3, the expected benefit from lying continues to be negative. As figure 4 shows, a low-type has no incentive to deviate when $K \leq 50$. However, unlike the case of a targeted tax, a low type actually does have an incentive to deviate under a head-tax when $K>50$. Thus, the expected benefit from lying is positive.

How do the two policies outlined above compare to the equilibrium of the currency policy? Pursuing a "min" strategy in the equilibrium outlined 


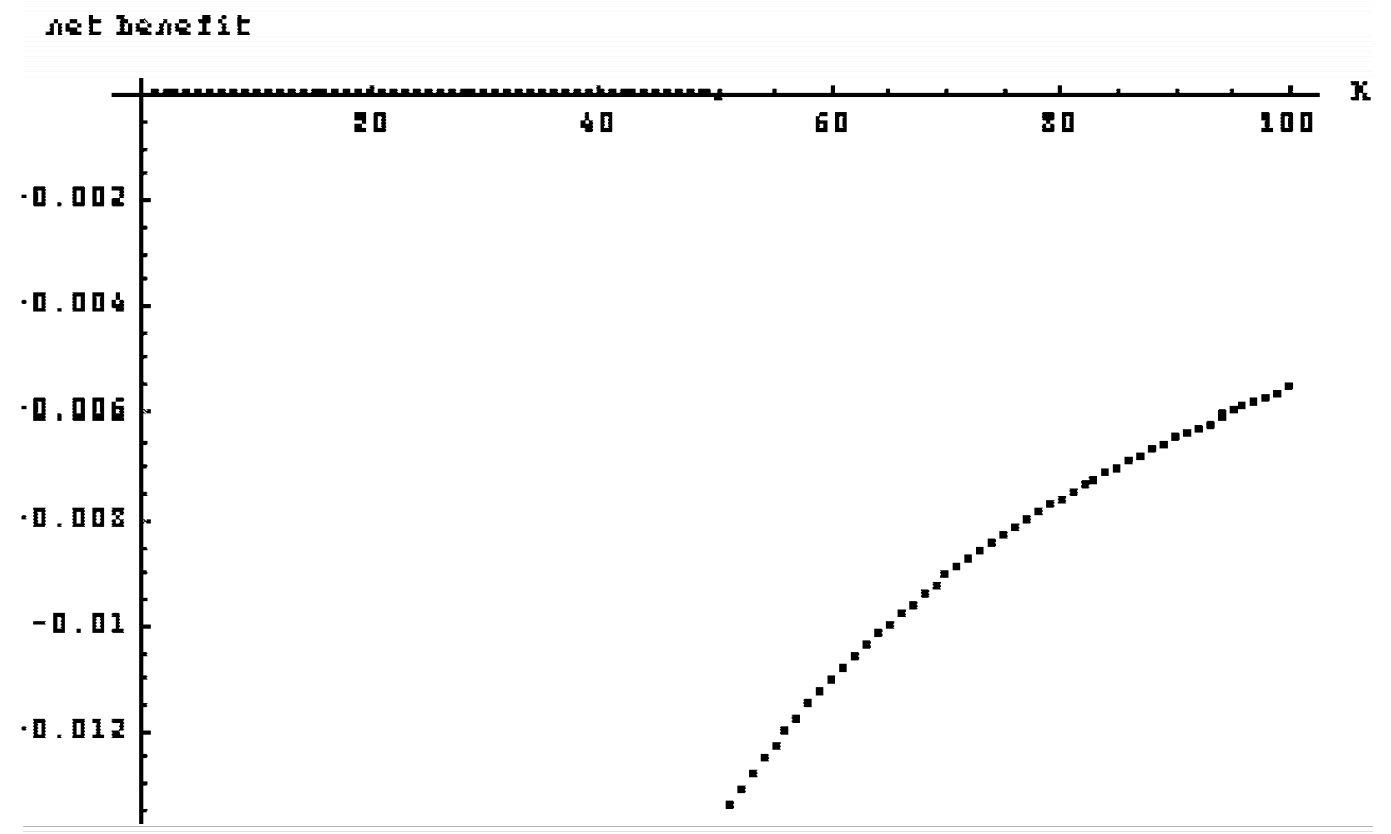

Figure 3: Net benefit to High-type deviating under head-tax

in Proposition 2 leads to full revelation. In this sense, it is analogous to truth-telling under the two policies considered above. As we saw earlier, it is never profitable for an individual to hold less than his minimum money holdings. Figures 5 and 6 describe net benefits of deviating to the right. In particular, we consider what incentive the individual might have to deviate from holding $m=c_{1} d\left(c_{1}, \theta\right)$ to $m^{\prime}=m+\varepsilon$, where $\varepsilon=0.01$.

As figure 5 indicates, a high-type individual has a positive incentive to deviate from a min-strategy for $K>50$. However, when $K \leq 50$, deviation entails a loss. ${ }^{18}$ Therefore, when $N=100$ and $\bar{q}=0.45$, under the binomial

\footnotetext{
${ }^{18} \mathrm{~A}$ cursory look at figure 5 provides the basic intuition. Suppose the net benefit is $4 \times 10^{-6}$ for all $K>50$ and the loss, $-1 \times 10^{-6}$ for $K \leq 50$. Then, in order for the expected benefit to be positive, it must be the case that $\operatorname{Pr}(K>50) \geq 0.2$. However, under the binomial distribution with $N=100$ and $\bar{q}=0.45, \operatorname{Pr}(K>50)=0.135<0.20$.
} 
net jenefit

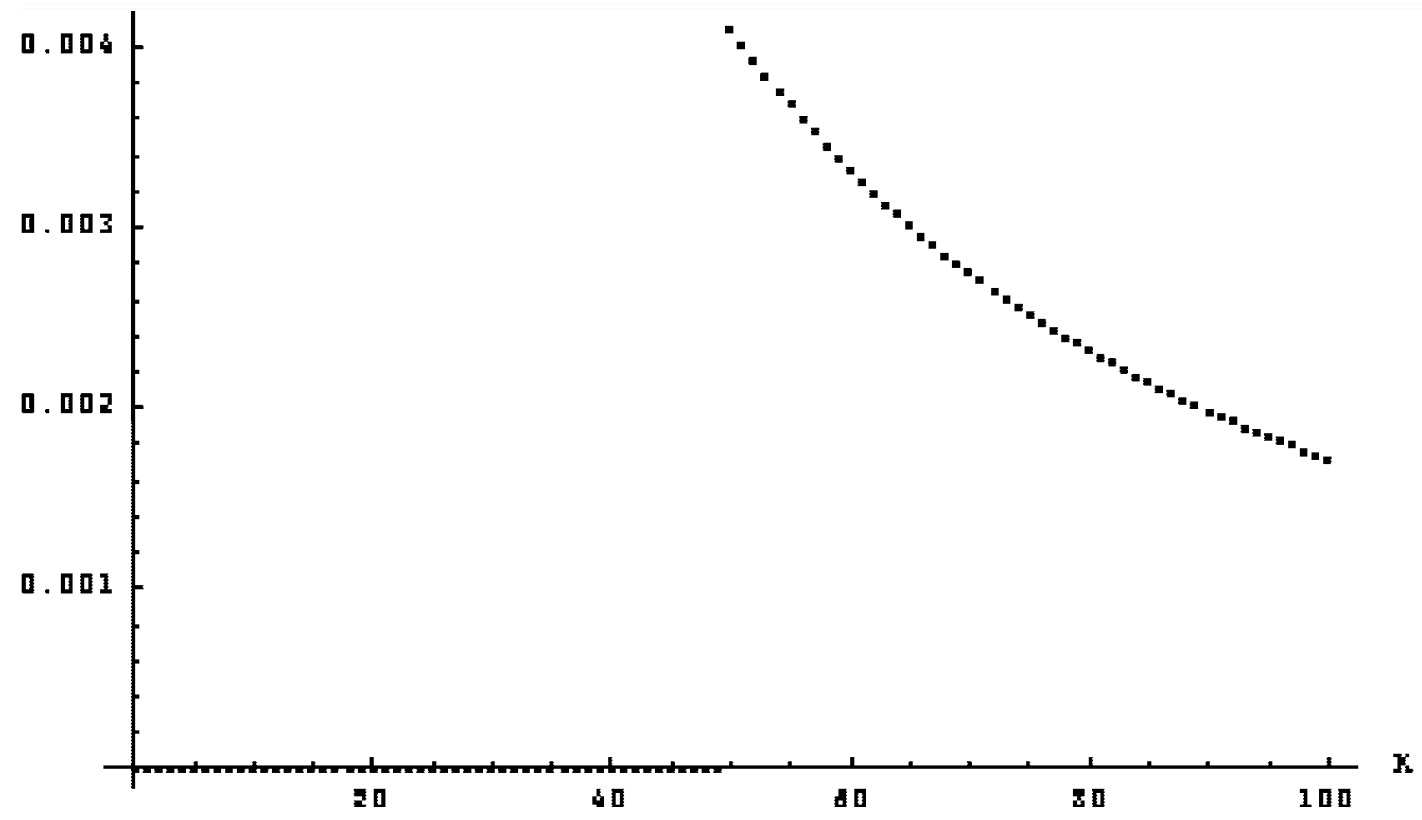

Figure 4: Net benefit to Low-type deviating under head-tax

distribution, the net benefit from deviating is negative. ${ }^{19}$ Figure 6 paints much the same picture as figure 5. Analogously, net expected benefits are negative and the low-type individual has no incentive to deviate from his min-strategy. ${ }^{20}$

\footnotetext{
${ }^{19}$ These results are for an epsilon-deviation. When a high-type individual holds enough extra money to convince the firm that there is one additional high type in the economy (i.e. $K+1$ high-types), net benefits are lower than -8 for all $0 \leq K \leq 100$.

${ }^{20}$ When a low-type individual holds enough extra money to convince the firm that there is one additional high type in the economy (i.e. $K+1$ high-types), net benefits are lower than -7 for all $0 \leq K \leq 100$.
} 


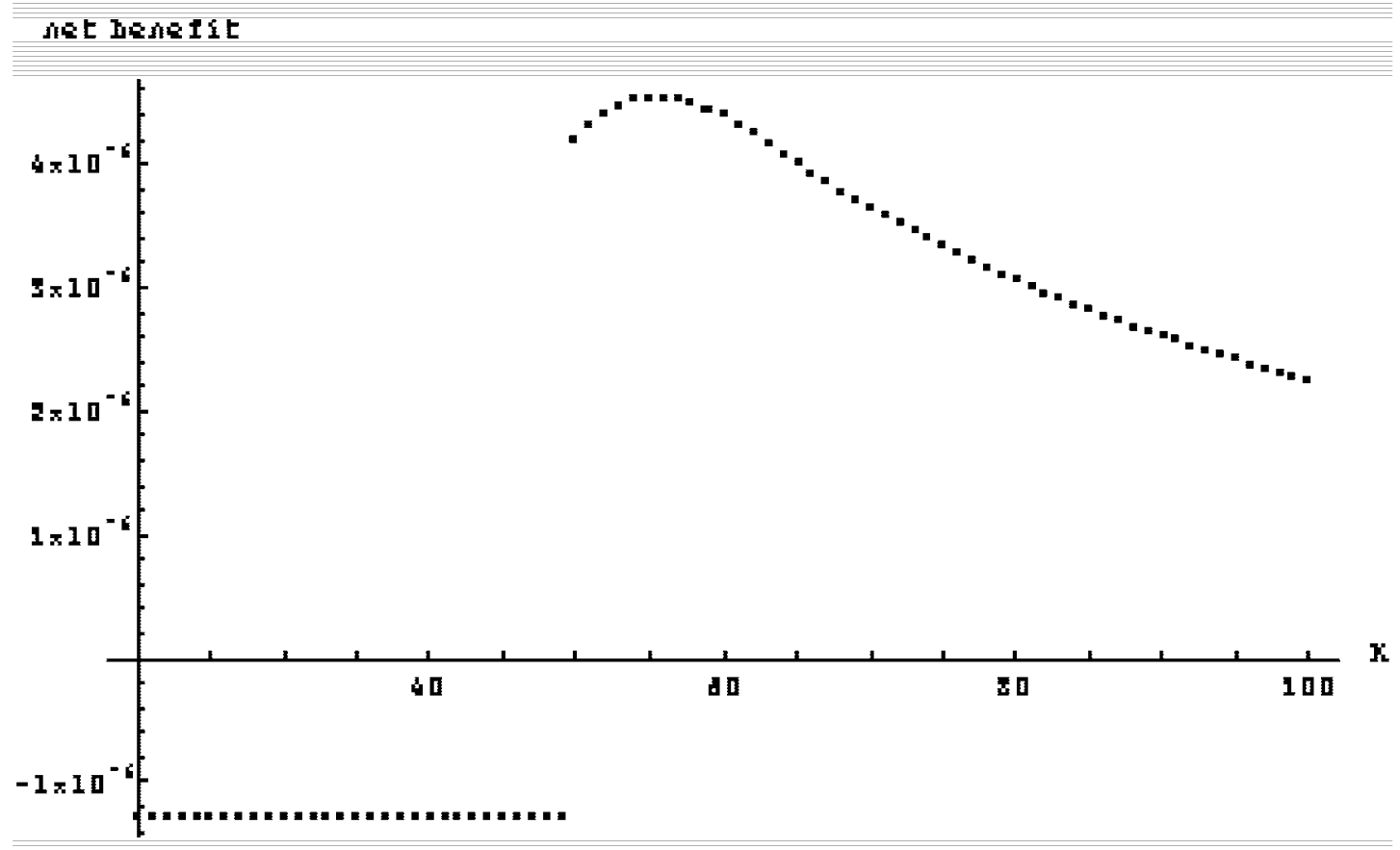

Figure 5: Net benefit to High-type deviating under local currency 
net bosefit

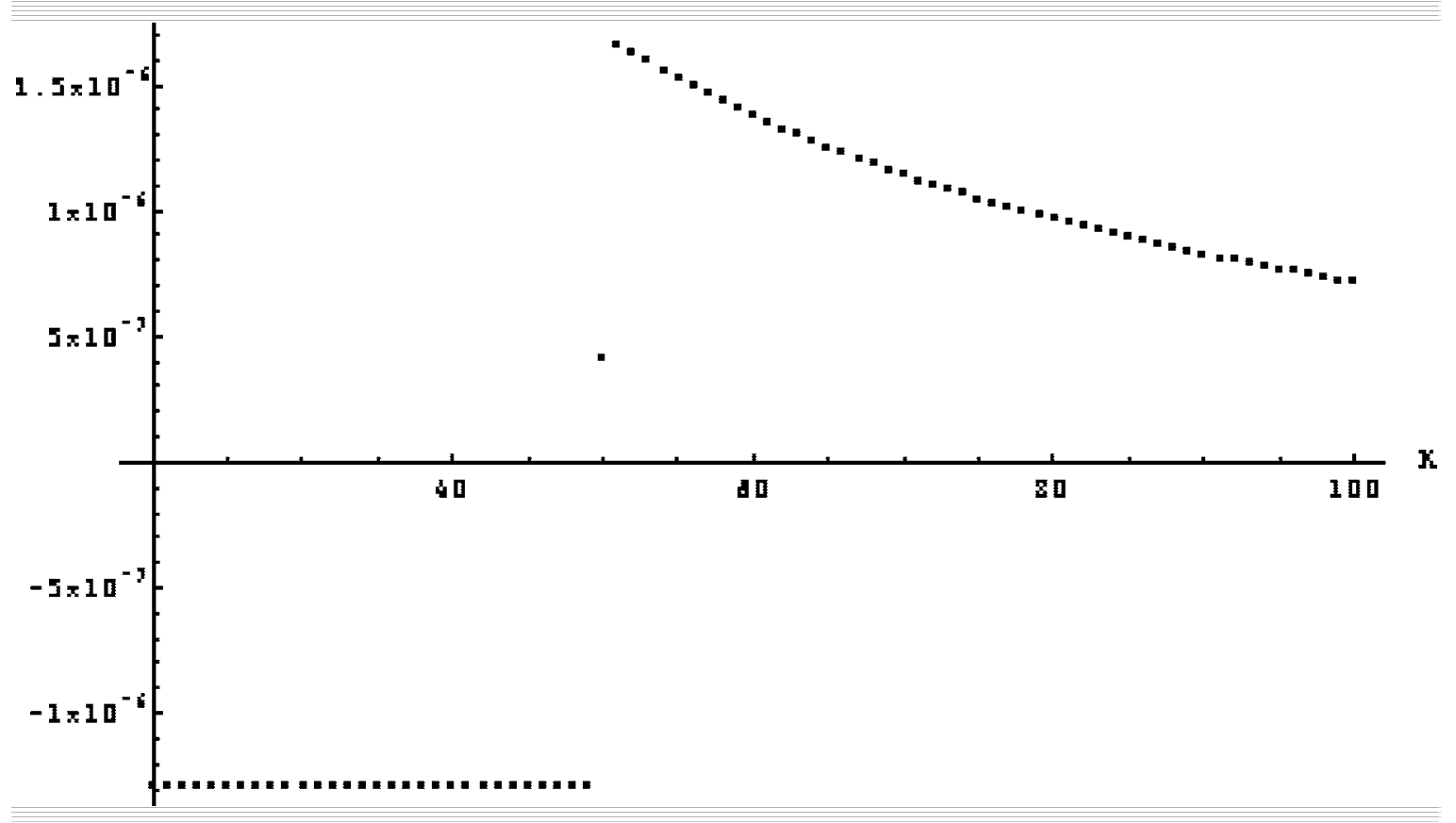

Figure 6: Net benefit to Low-type deviating under local currency 


\section{CESifo Working Paper Series}

(for full list see www.cesifo.de)

848 V. Bhaskar and Steinar Holden, Wage Differentiation via Subsidised General Training, January 2003

849 Paloma Lopez-Garcia, Labour Market Performance and Start-up Costs: OECD Evidence, January 2003

850 Christian Keuschnigg and Soren Bo Nielsen, Public Policy for Start-up Entrepreneurship with Venture Capital and Bank Finance, January 2003

851 Yin-Wong Cheung, Menzie D. Chinn, and Eiji Fujii, China, Hong Kong, and Taiwan: A Quantitative Assessment of Real and Financial Integration, January 2003

852 Gregory D. Hess, The Economic Welfare Cost of Conflict: An Empirical Assessment, February 2003

853 Douglas J. Cumming and Jeffrey G. MacIntosh, Comparative Venture Capital Governance. Private versus Labour Sponsored Venture Capital Funds, February 2003

854 Eckhard Janeba and John Douglas Wilson, Decentralization and International Tax Competition, February 2003

855 Tapio Palokangas, Capital Accumulation and Employment Cycles in a Model of Creative Destruction, February 2003

856 Brendan Walsh, When Unemployment Disappears: Ireland in the 1990s, February 2003

857 Luis H. R. Alvarez and Erkki Koskela, A General Approach to the Stochastic Rotation Problem with Amenity Valuation, February 2003

858 Christian Schultz, Strategic Campaigns and Redistributive Politics, February 2003

859 Ernst Fehr and Joseph Henrich, Is Strong Reciprocity a Maladaptation? On the Evolutionary Foundations of Human Altruism, February 2003

860 Haizhou Huang, Dalia Marin, and Chenggang Xu, Financial Crisis, Economic Recovery and Banking Development in Former Soviet Union Economies, February 2003

861 Pedro Cardoso and Bernard M.S. van Praag, How Sustainable Are Old-age Pensions in a Shrinking Population with Endogenous Labour Supply?, February 2003

862 Volker Meier, Efficient Transfer of Aging Provisions in Private Health Insurance, February 2003

863 Edward Castronova, Theory of the Avatar, February 2003 
864 Robert S. Chirinko, Hans van Ees, Harry Garretsen, and Elmer Sterken, Investor Protections and Concentrated Ownership: Assessing Corporate Control Mechanisms in the Netherlands, February 2003

865 Bernard M.S. van Praag and Pedro Cardoso, The Mix Between Pay-as-you-go and Funded Pensions and what Demography has to do with it, February 2003

866 Ernst Fehr, Urs Fischbacher, Bernhard von Rosenbladt, Jürgen Schupp, and Gert G. Wagner, A Nation-Wide Laboratory. Examining Trust and Trustworthiness by Integrating Behavioral Experiments into Representative Survey, February 2003

867 Frank Heinemann, The Inflationary Impact of Wage Indexation, February 2003

868 Eytan Sheshinski, Bounded Rationality and Socially Optimal Limits on Choice in a Self-Selection Model, February 2003

869 M. Hashem Pesaran, Estimation and Inference in Large Heterogenous Panels with Cross Section Dependence, February 2003

870 Luis H. R. Alvarez and Erkki Koskela, On the Tree-Cutting Problem under Interest Rate and Forest Value Uncertainty, February 2003

871 Norbert Berthold and Rainer Fehn, Unemployment in Germany: Reasons and Remedies, February 2003

872 Clemens Fuest, Bernd Huber, and Philipp Tilleßen, Tax Policy and Entrepreneurship in the Presence of Asymmetric Information in Capital Markets, February 2003

873 Eytan Sheshinski, Optimum and Risk-Class Pricing of Annuities, February 2003

874 Willi Leibfritz, Paul O'Brien and Jean-Christophe Dumont, Effects of Immigration on Labour Markets and Government Budgets - An Overview, February 2003

875 M. Hashem Pesaran and Allan Timmermann, How Costly is it to Ignore Breaks when Forecasting the Direction of a Time Series?, February 2003

876 Thorvaldur Gylfason and Gylfi Zoega, Education, Social Equality and Economic Growth: A View of the Landscape, February 2003

877 Robin Boadway and Jean-François Tremblay, Public Economics and Startup Entrepreneurs, February 2003

878 Erkki Koskela and Roope Uusitalo, The Un-Intended Convergence: How the Finnish Unemployment Reached the European Level, February 2003

879 Robert Fenge and Volker Meier, Pensions and Fertility Incentives, February 2003

880 Eytan Sheshinski, Note on Income Taxation and Occupational Choice, February 2003 
881 A B Atkinson, Income Inequality in OECD Countries: Data and Explanations, February 2003

882 Thomas Gehrig and Rune Stenbacka, Venture Cycles: Theory and Evidence, February 2003

883 Ralf Becker and Thomas Hellmann, The Genesis of Venture Capital - Lessons from the German Experience, March 2003

884 Eytan Sheshinski, Note on the Optimum Pricing of Annuities, March 2003

885 Paul De Grauwe and Magdalena Polan, Globalisation and Social Spending, March 2003

886 F. van der Ploeg, Do Social Policies Harm Employment and Growth?, March 2003

887 Mirjam van Praag, Initial Capital Constraints Hinder Entrepreneurial Venture Performance: An empirical analysis, March 2003

888 Bernard Steunenberg, Coordinating Sectoral Policymaking: Searching for Countervailing Mechanisms in the EU Legislative Process, March 2003

889 Eytan Sheshinski, Optimum Delayed Retirement Credit, March 2003

890 Frederick van der Ploeg, Rolling Back the Public Sector - Differential effects on employment, investment and growth, March 2003

891 Paul De Grauwe and Marc-Alexandre Sénégas, Monetary Policy in EMU when the Transmission is Asymmetric and Uncertain, March 2003

892 Steffen Huck and Kai A. Konrad, Strategic Trade Policy and the Home Bias in Firm Ownership Structure, March 2003

893 Harry Flam, Turkey and the EU: Politics and Economics of Accession, March 2003

894 Mathias Hoffmann and Ronald MacDonald, A Re-examination of the Link between Real Exchange Rates and Real Interest Rate Differentials, March 2003

895 Badi H. Baltagi, Espen Bratberg, and Tor Helge Holmås, A Panel Data Study of Physicians' Labor Supply: The Case of Norway, March 2003

896 Dennis C. Mueller, Rights and Citizenship in the European Union, March 2003

897 Jeremy Edwards, Gains from Trade in Tax Revenue and the Efficiency Case for Trade Taxes, March 2003

898 Rainer Fehn and Thomas Fuchs, Capital Market Institutions and Venture Capital: Do They Affect Unemployment and Labour Demand?, March 2003

899 Ronald MacDonald and Cezary Wójcik, Catching Up: The Role of Demand, Supply and Regulated Price Effects on the Real Exchange Rates of Four Accession Countries, March 2003 
900 R. Selten, M. Schreckenberg, T. Pitz, T. Chmura, and S. Kube, Experiments and Simulations on Day-to-Day Route Choice-Behaviour, April 2003

901 Stergios Skaperdas, Restraining the Genuine Homo Economicus: Why the Economy Cannot be Divorced from its Governance, April 2003

902 Yin-Wong Cheung, Menzie D. Chinn, and Antonio Garcia Pascual, What Do We Know about Recent Exchange Rate Models? In-Sample Fit and Out-of-Sample Performance Evaluated, April 2003

903 Mika Widgrén, Enlargements and the Principles of Designing EU - Decision-Making Procedures, April 2003

904 Phornchanok Cumperayot, Dusting off the Perception of Risk and Returns in FOREX Markets, April 2003

905 Kai A Konrad, Inverse Campaigning, April 2003

906 Lars P. Feld and Stefan Voigt, Economic Growth and Judicial Independence: Cross Country Evidence Using a New Set of Indicators, April 2003

907 Giuseppe Bertola and Pietro Garibaldi, The Structure and History of Italian Unemployment, April 2003

908 Robert A.J. Dur and Otto H. Swank, Producing and Manipulating Information, April 2003

909 Christian Gollier, Collective Risk-Taking Decisions with Heterogeneous Beliefs, April 2003

910 Alexander F Wagner, Mathias Dufour, and Friedrich Schneider, Satisfaction not Guaranteed - Institutions and Satisfaction with Democracy in Western Europe, April 2003

911 Ngo Van Long, Raymond Riezman, and Antoine Soubeyran, Trade, Wage Gaps, and Specific Human Capital Accumulation, April 2003

912 Andrea Goldstein, Privatization in Italy 1993-2002: Goals, Institutions, Outcomes, and Outstanding Issues, April 2003

913 Rajshri Jayaraman and Mandar Oak, The Signaling Role of Municipal Currencies in Local Development, April 2003 